\title{
The regulatory role of Fos related antigen- 1 in inflammatory bowel disease
}

\author{
XIANREN WANG ${ }^{1,2^{*}}$, RENLE GUO $3^{*}$, YANFENG LV $^{2}$ and RONGZHAN FU ${ }^{1}$ \\ ${ }^{1}$ Department of Breast and Thyroid Surgery, Subsidiary Qianfoshan Hospital of Shandong University, Jinan, \\ Shandong 250014; ${ }^{2}$ Department of Anorectal Surgery, The Second Hospital of Shandong University, Jinan, \\ Shandong 250131; ${ }^{3}$ Department of Vascular Surgery, Tai'an Central Hospital, Tai'an, Shandong 271099, P.R. China
}

Received August 17, 2016; Accepted October 26, 2017

DOI: $10.3892 / \mathrm{mmr} .2017 .8071$

\begin{abstract}
The etiology of inflammatory bowel disease (IBD) remains unclear. The ratio of Fos related antigen-1 (Fra-1)-positive intestinal mucosa epithelial cells is significantly increased in active IBD. This study intends to explore the regulatory role of Fra-1 in IBD. The Fra-1 eukaryotic expression vector was constructed and stably transfected to establish the Fra-1 overexpression HCT-116 (116-Fra-1) intestinal epithelial cell line. The impact of Fra-1 overexpression on intestinal mucosal epithelial cell damage repair function was tested using a scratch assay. The role of Fra-1 overexpression on intestinal mucosal epithelial cell proliferation was evaluated using a Cell Counting Kit-8 assay. Apoptosis related proteins, B-cell lymphoma 2 (Bcl-2), c-Myc, Survivin and Bcl-extra large (Bcl-xL), expression levels were detected by western blotting. Fra-1 suppressed intestinal mucosal epithelial cell damage repair and proliferation. Fra-1 inhibited the protein levels of Bcl-2, c-Myc, Survivin, and Bcl-xL. Fra-1 overexpression in intestinal mucosal epithelial cells may restrain damage repair after intestinal mucosal injury in IBD remittent period through weakening the protective effect of intestinal mucosa, thus increasing the risk of recurrence. Therefore, suppressing Fra-1 expression in intestinal mucosal epithelial cells may contribute to IBD remittent maintenance and recurrence delay.
\end{abstract}

\section{Introduction}

Inflammatory bowel disease (IBD) is a type of chronic inflammation of the gastrointestinal tract (1). It is generally believed that IBD is related to genetic factors, environmental factors, and imbalance of intestinal flora $(2,3)$. In the clinical treatment,

Correspondence to: Dr Rongzhan Fu, Department of Breast and Thyroid Surgery, Subsidiary Qianfoshan Hospital of Shandong University, 66 Jingshi Road, Jinan, Shandong 250014, P.R. China

E-mail: rongzhanfuqwe@sina.com

*Contributed equally

Key words: inflammatory bowel disease, Fra-1, cell apoptosis the vast majority of patients can be alleviated through the immunomodulatory therapy, especially the immune inhibitors and biological agents. However, most patients will relapse while the specific mechanism is still unclear. Investigation of the relapse mechanism can provide suggestion to explore the potential prediction biomarker for IBD recurrence and search for new drug targets to prevent recurrence and maintain remission. At present, the markers used to predict IBD recurrence include C-reactive protein (CRP), erythrocyte sedimentation rate (ESR), prostaglandin E2 protein, and fecalcal protectin, etc. $(4,5)$. However, most of them are only the early signs of intestinal mucosal inflammation, which cannot be applied to predict recurrence in patients at long-term remission or mucosal healing stage. The number of Fos related antigen-1 (Fra-1) positive intestinal mucosal epithelial cells in active and remittent IBD patients are obviously higher than the healthy people (6-10). Vaishnava et al (11) followed up 32 IBD patients in active or remittent stage for 10 years and found that Fra-1 expression in intestinal mucosa epithelial cells were closely associated with the length of active or remittent stage. it suggested that Fra-1 level detection may facilitate to predict recurrence in IBD patients without inflammation in intestinal mucosa. Meanwhile, Fra-1 high expression in intestinal mucosa epithelial cells may also be one of the reasons of IBD relapse. However, the specific mechanism of Fra-1 in promoting IBD recurrence is still unclear. The exploration on it may provide new strategy for the maintenance treatment of IBD in remittent stage. This study aims to discuss the mechanism of Fra-1 in promoting IBD recurrence, thus to provide new idea for IBD treatment.

\section{Materials and methods}

Materials. Human intestinal epithelial cell line HCT-116 was purchased from ATCC. RPMI-1640 medium, FBS, Trypsin-EDTA $(0.25 \%)$, penicillin-streptomycin, and PBS were from Gibco. DMSO was from Sky Biological Technology Co., Ltd. (Jining, China). Lipofectamine ${ }^{\circledR} 2000$ was from Invitrogen; Thermo Fisher Scientific, Inc. (Waltham, MA, USA). Cell Counting Kit-8 (CCK-8) was from Dojindo Molecular Technologies, Inc. (Rockville, MD, USA). RNA extraction kit was from Takam Biotechnology Co., Ltd (Japan). Absolute methanol, ethanol, isopropanol, chloroform, and 
methanal were from Sinopharm Chemical Reagent Co., Ltd. (Shanghai, China). Primers were designed and synthetized by Sangon Biotech Co., Ltd. (Shanghai, China).

Instruments. Cell incubator was from Baimei. Biosafety cabinet was from Baker Co. (Sanford, ME, USA). DK22 electric heating water bath was from Shanghai Laboratory Equipment Co., Ltd. (Shanghai, China). Electronic analytical balance was from Beijing Biological Technology Co., Ltd. (Beijing, China). High-speed centrifuge was from Eppendorf (Hamburg, Germany). Millipore-Q ultrapure water system was from EMD Millipore (Billerica, MA, USA).

Human Fra-1 expression vector construction. The specific recognition sequences for $\mathrm{XhoI}$ and $\mathrm{BamHI}$ sites were added to the two ends of the amplification primer of Fra-1 coding sequence (Fig. 1). cDNA from CACO-2 cells were selected as template for PCR amplification $\left(95^{\circ} \mathrm{C} 1 \mathrm{~min}, 35\right.$ circles consisting of $95^{\circ} \mathrm{C} 30 \mathrm{sec}, 55^{\circ} \mathrm{C} 30 \mathrm{sec}, 72^{\circ} \mathrm{C} 1 \mathrm{~min}$, and $72^{\circ} \mathrm{C}$ $5 \mathrm{~min})$ in a total volume of $20 \mu \mathrm{l}(0.1 \mu \mathrm{l}$ Takara Taq, $2 \mu \mathrm{l} 10 \mathrm{X}$ Taq buffer, $1.6 \mu 1$ DNTP mixture, $1 \mu \mathrm{l}$ cDNA, $1 \mu \mathrm{l}$ forward and

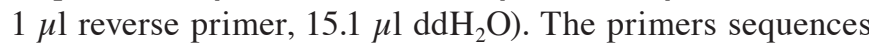
were as follows: Forward 5-TGTTCGCCGTCCTGGAA-3 and reverse 5-CGCCATAGGCGTAGTAATCGA-3. After product purification and double enzyme digestion, the sequence was connected to the pcDNA3.1(-) vector. The plasmid was sequenced (ABI3130 Sanger) after amplification and the results showed that all of the 6 vectors contained Fra-1 coding sequence, which were completely consistent with Fra-1 sequence in NCBI database. It suggested the Fra-1 expression vector was successfully constructed.

Fra-1 transfection. HCT-116 cells were cultured in high-glucose DMEM medium and digested by enzyme. Then the cells were suspended in $10 \%$ FBS and seeded in 24-well plate at the density of 70-80\%. pGPU6/GFP Neo Fra-1, pGPU6/GFP Neo Con, or pGPU6/GFP Neo GAPDH were diluted in $50 \mu 1$ Opti-MEM, while $1.5 \mu 1$ Lipofectamine ${ }^{\circledR} 2000$ was diluted in $50 \mu \mathrm{l}$ Opti-MEM for $5 \mathrm{~min}$, respectively. Then they were mixed at room temperature for $20 \mathrm{~min}$. Next, the mixture was added to the cells for transfection for 48-72 $\mathrm{h}$.

CCK- 8 assay. The cells were digested and centrifuged at 600-800 rpm for $5 \mathrm{~min}$. After washed by PBS, the cells were seeded in 96-well plate at 5,000 cells/cell. CCK-8 was used to test the cell viability every $24 \mathrm{~h}$ for 3 continuous days to draw the proliferation curve.

Damage repair assay. The cells were seeded in six-well plate at $1 \times 10^{5}$ cells/well. After the cell density reached $100 \%$, a $200 \mu 1$ tip was adopted to scratch three lines on the bottom. Eight fields were randomly selected under the microscope to record the width every $24 \mathrm{~h}$. The reside width percentage was calculated to draw the curve.

Western blotting. The cells were treated by lysis buffer to extract the protein. After isolation, the protein was quantified by BCA method and boiled for $5 \mathrm{~min}$. The protein $(30 \mu \mathrm{g}$ per each sample) was separated by $10 \%$ SDS-PAGE and transferred to PVDF membrane. After blocked at room temperature for $1 \mathrm{~h}$, the membrane was incubated in primary antibody $(1: 1,000)$ at $4^{\circ} \mathrm{C}$ overnight. After washed by PBST for three times, the membrane was further incubated in secondary antibody at room temperature. At last, the membrane was treated by ECL reagent for $5 \mathrm{~min}$ to obtain the image. For measurement of caspase- 3 activation, anti-caspase- 3 antibody was used to measure the full length and cleaved form of caspase- 3 by western blot.

Immunohistochemistry staining. 13 patients with IBD in active phase from June 2015 to January 2016 from the Department of Anus and Intestine Surgery, The Second Hospital of Shandong University (Jinan, China) were included in this study. All patients were diagnosed and confirmed as IBD according to examinations. Meanwhile, 13 individuals from car accidents were included as a control group. The intestinal mucosa were collected from patients and controls for immunohistochemical staining and were dehydrated and embedded in paraffin following routine methods. The paraffin sections were removed paraffin, and then immersed in the distilled water following routine methods. Afterwards, rinsing the paraffin sections in PBS-T and then blocked with Ultra V Block followed by washing and addition of primary antibody against Fra-1 (Santa Cruz Biotechnology, Inc., Dallas, Texas, USA) and incubated for 1-2 $\mathrm{h}$. Then wash and add primary antibody enhancer with incubation for $30 \mathrm{~min}$ followed by addition of HRP-conjugated secondary antibody (anti-mouse HRP secondary antibody; Abcam, Cambridge, MA, USA). At last, DAB Plus Substrate (DAB substrate kit; Abcam) was added for developing. Five random fields were imaged per slide and positive cells were counted manually by observation, then the average number of positive cells/field was calculated. Examples of optical fields that exhibited negative or strong positive staining for Fra-1 were shown.

Statistical analysis. At least three independent experiments were performed for each assay. All data analysis was performed on IBM SPSS 19.0 software (IBM Corp., Armonk, NY, USA). Measurement data was presented as mean \pm standard deviation and compared by t-test, Spearman rank correlation analysis, or logistic regression analysis when necessary. $\mathrm{P}<0.05$ was considered to indicate a statistically significant difference.

\section{Results}

Fra-1 overexpression HCT-116 cell line construction. HCT-116 cells were transfected with Fra-1 expression vector and screened by G418 $(600 \mu \mathrm{g} / \mathrm{ml})$ to select the monoclonal cell line. qPCR was applied to verify the cell line with highest expression, named 116-Fra-1. The cells transfected with pcDNA3.1 (-) empty vector and screened by G418 which was named as 116-neo group. qPCR and western blotting both confirmed that Fra-1 expression level in 116-Fra-1 cells $(3,500 \pm 123$ for PCR and $0.53 \pm 0.11$ for western (ratio to $\beta$-actin)) was obviously higher than that in 116-neo cells $(0.7 \pm 0.2$ for $\mathrm{PCR}$ and $0.12 \pm 0.02$ for western) $(\mathrm{P}<0.0001$ for PCR and P $<0.05$ for western) (Fig. 2).

Fra-1 suppressed intestinal mucosal epithelial cell proliferation and damage repair. Damage repair model was applied 


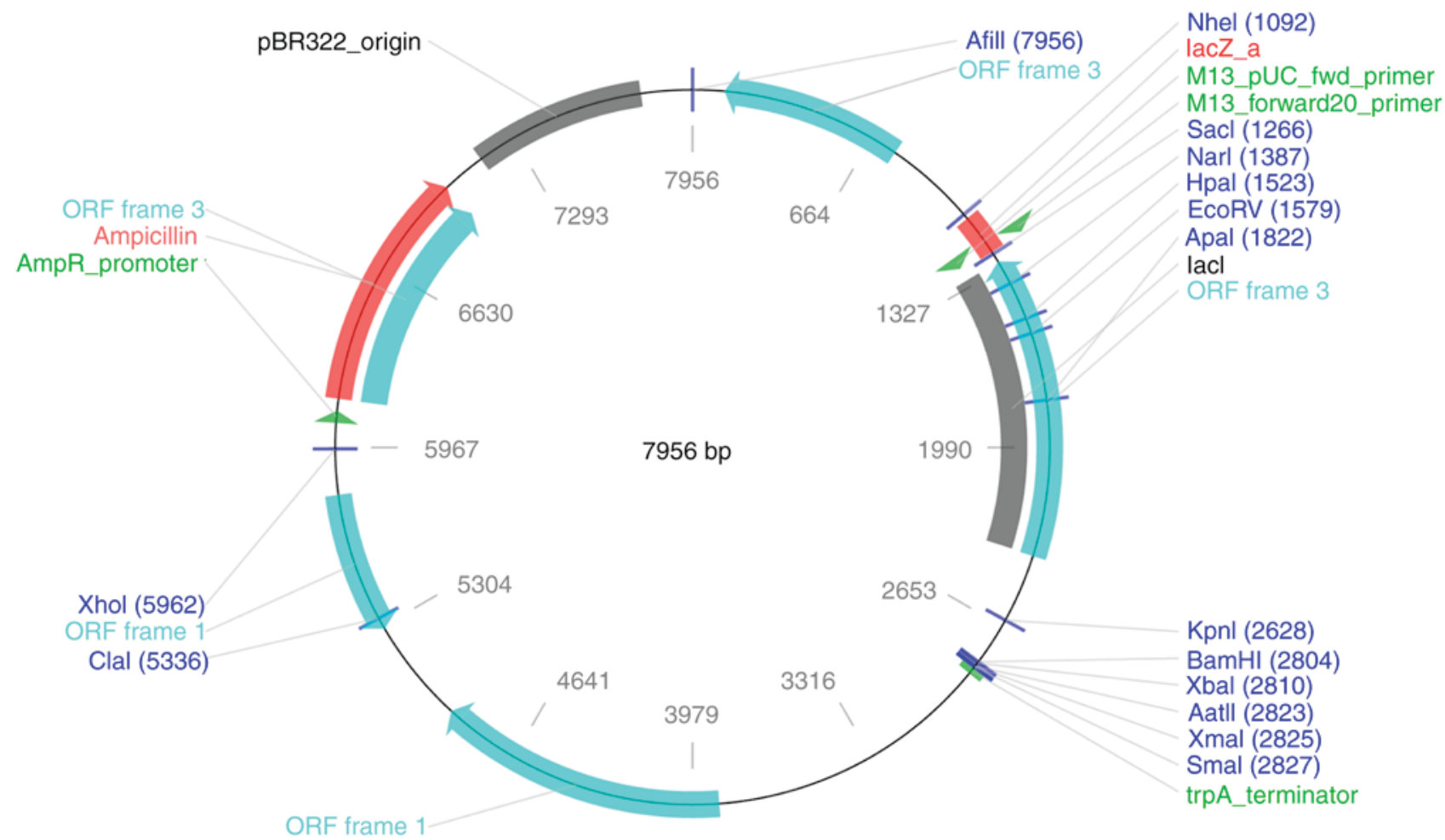

Figure 1. Human Fra-1 expression vector construction. Fra-1, Fos related antigen-1.

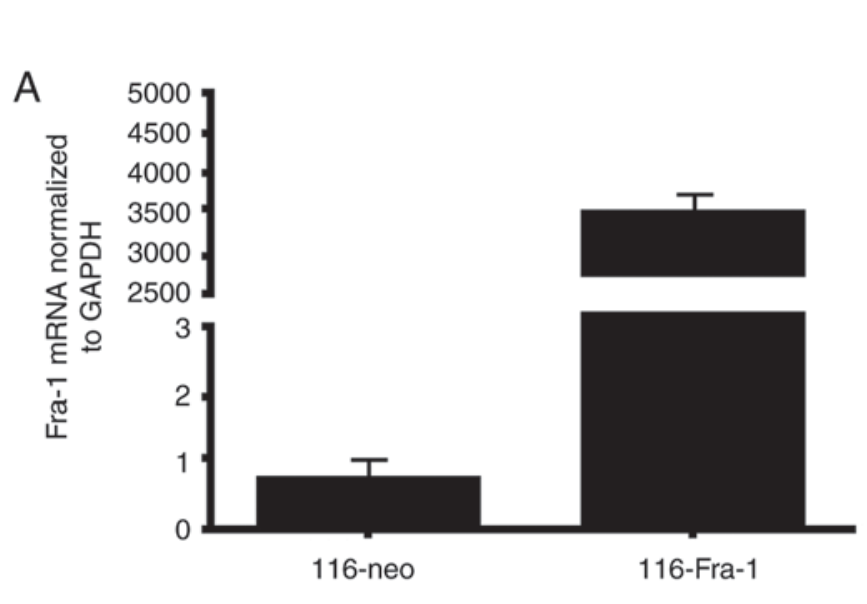

B
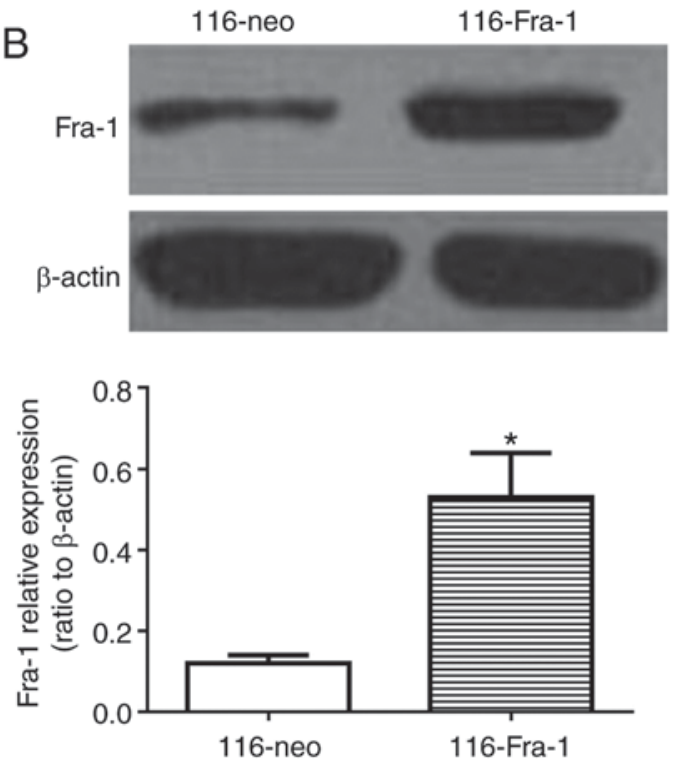

Figure 2. Fra-1 overexpression in HCT-116 cell line construction. RNA or protein were isolated from HCT-116 cells for analysis of Fra- 1 mRNA expression by quantitative polymerase chain reaction (A) or Fra-1 protein expression by western blot (B). Quantitative analysis of protein expression as a ratio to $\beta$-actin was also shown in (B). "Compared with 116-neo, $\mathrm{P}<0.05$. Data were presented as mean \pm standard deviation. Fra-1, Fos related antigen-1.

to investigate the impact of Fra-1 on intestinal epithelial cell damage. It was showed that at $24 \mathrm{~h}$ after damage, the repair effect of 116-Fra-1 cells were lower than 116-neo cells. The repair schedule exhibited significant difference at $48 \mathrm{~h}$ after damage ( $\mathrm{P}<0.05$; Fig. 3A). CCK-8 assay revealed that 116-Fra-1 cell proliferative rate was obviously lower than 116-neo cells (Fig. 3B), suggesting that Fra-1 may interfere intestinal epithelial mucosa barrier repair through affecting cell proliferation and migration.
Fra-1 overexpression regulated apoptosis related protein expression. Western blotting demonstrated that Fra-1 overexpression markedly suppressed Bcl-2 (0.11 \pm 0.02 vs. $0.63 \pm 0.21, \mathrm{P}<0.05)$, Survivin $(0.21 \pm 0.03$ vs. $0.83 \pm 0.26, \mathrm{P}<0.05)$, Bcl-xL $(0.45 \pm 0.09$ vs. $0.95 \pm 0.31, \mathrm{P}<0.05)$, and c-Myc expression $(0.08 \pm 0.03$ vs. $0.51 \pm 0.18, \mathrm{P}<0.05)$ in $\mathrm{HCT}-116$ cells compared with 116-neo group (Fig. 4A). Consistently, increased active of caspase- 3 was also observed in HCT-116 cells $(0.5 \pm 0.05)$ compared with 116-neo group $(0.3 \pm 0.02)(\mathrm{P}<0.01)$ (Fig. 4B). 

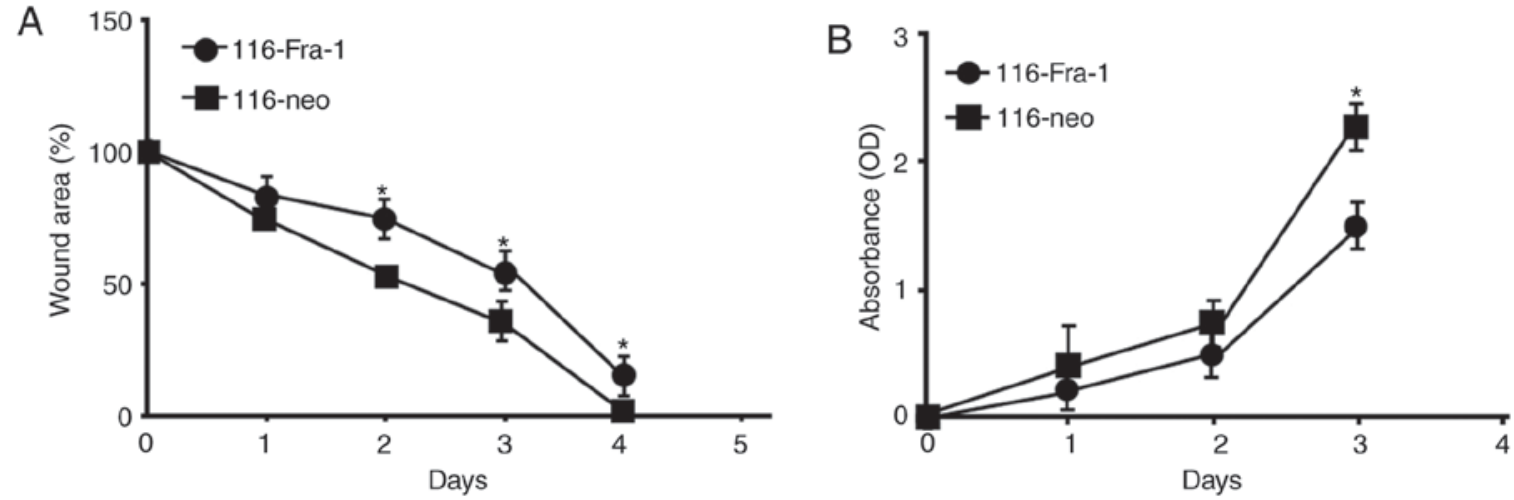

Figure 3. Fra-1 suppressed intestinal mucosal epithelial cell proliferation and damage repair. (A) Damage repair assay detection of cell repairmen ability. (B) Cell Counting Kit-8 assay detection of cell proliferation. ${ }^{*}$ Compared with 116-neo, $\mathrm{P}<0.05$. Data were presented as mean \pm standard deviation. Fra-1, Fos related antigen-1.

A
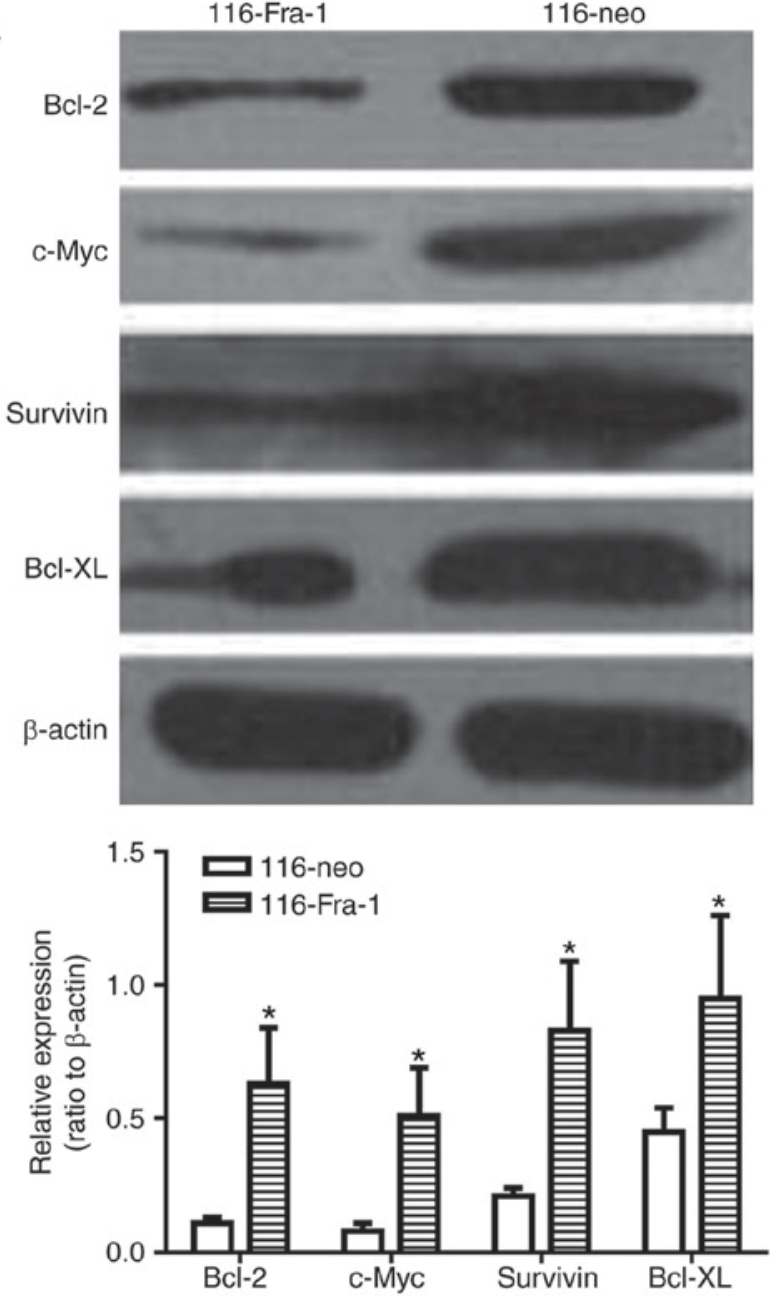

B
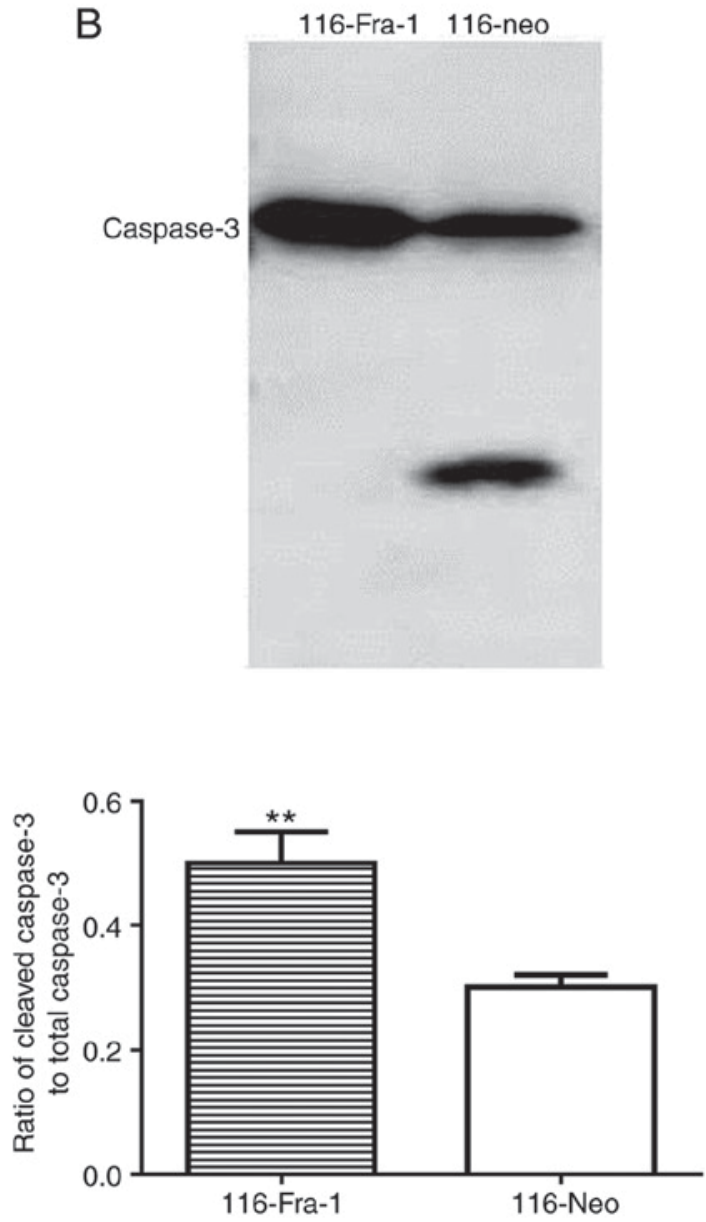

Figure 4. Fra-1 overexpression regulated apoptosis related protein expression and caspase-3 activation. Proteins were isolated from HCT cells after transfected with Fra-1 followed by analysis of (A) apoptosis-related protein expression and (B) caspase-3 expression by western blotting. Compared with 116 -neo, ${ }^{*} \mathrm{P}<0.05$; ${ }^{* *} \mathrm{P}<0.01$. Quantitative analysis of protein expression as a ratio to $\beta$-actin was also shown. Data were presented as mean \pm standard deviation. Fra- 1, Fos related antigen-1; Bcl, B-cell lymphoma.

Fra-1 overexpression restrained STAT1, STAT3, STAT6, ERK1/2, and AKT expression. To further investigate the specific mechanism of Fra-1 on influencing Bcl-2, Survivin, Bcl-xL, and c-Myc expression, western blotting was adopted to evaluate the impact of Fra-1 overexpression on a variety of signaling pathways. It was presented that Fra-1 overexpression inhibited STAT1 $(0.36 \pm 0.02$ vs. $0.92 \pm 0.22, \mathrm{P}<0.05)$, STAT3 $(0.01 \pm 0.003$ vs. $0.39 \pm 0.09$, $\mathrm{P}<0.05)$, STAT6 ( $0.41 \pm 0.08$ vs. $0.93 \pm 0.25, \mathrm{P}<0.05)$, ERK $1 / 2$ $(0.56 \pm 0.12$ vs. $0.92 \pm 0.21, \mathrm{P}<0.05)$, and AKT $(0.26 \pm 0.06$ 


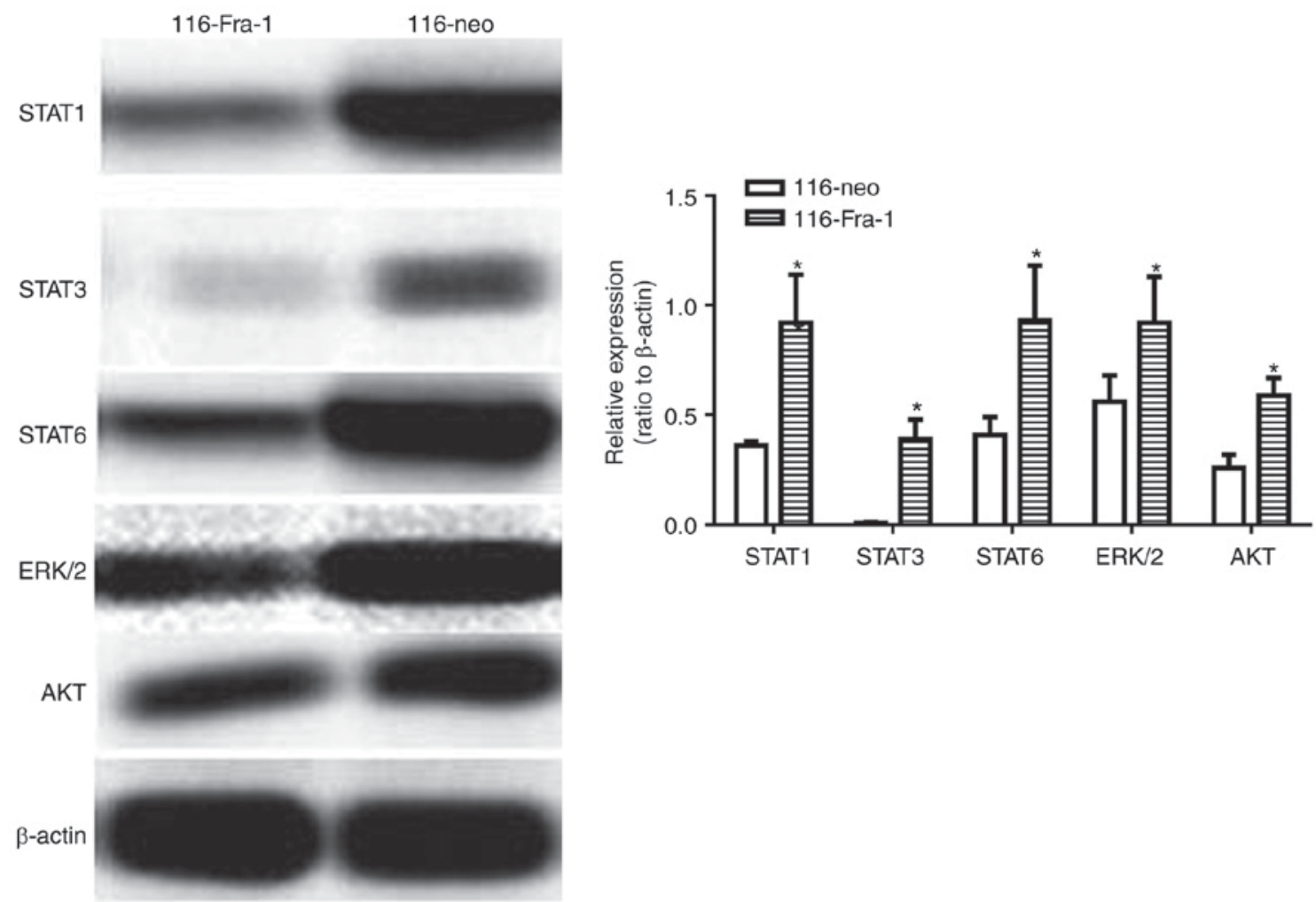

Figure 5. Fra-1 overexpression restrained STAT1, STAT3, STAT6, ERK1/2, and AKT expression. Proteins were extracted from HCT cells after transfected with Fra-1 for the analysis of the expression of STAT1, STAT3, STAT6, ERK1/2 and AKT by western blotting. "Compared with 116-neo, P<0.05. Quantitative analysis of protein expression as a ratio to $\beta$-actin was also shown. Data were presented as mean \pm standard deviation. Fra- 1 , Fos related antigen-1.
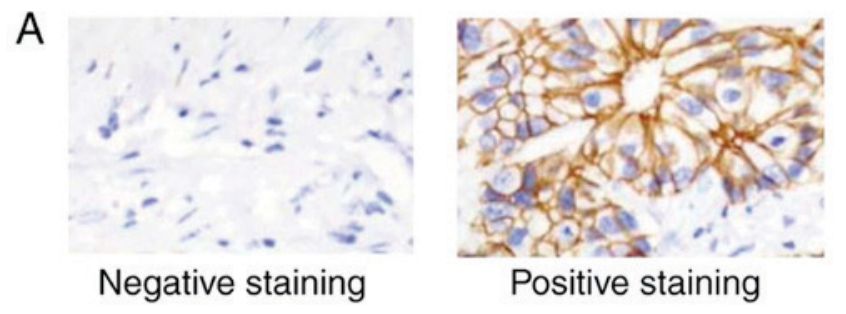

B

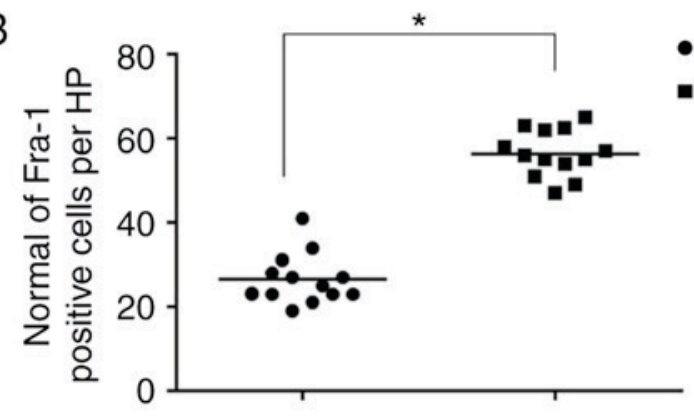

- Normal

- IBD active phase

Figure 6. Immunohistochemistry detection of Fra-1 expression in active stage of IBD and normal control. The intestinal mucosa were collected from patients and controls for immunohistochemical staining of Fra-1 (magnification, x40). (A) Negative and positive staining graph; (B) Quantitative analysis of the number of Fra-1 positive cells. ${ }^{*} \mathrm{P}<0.05$ vs. normal control. Data were presented as mean \pm standard deviation.

vs. $0.59 \pm 0.08, \mathrm{P}<0.05)$ signaling pathway, of which it showed the most significant effect on STAT3 signaling pathway (Fig. 5).

Fra-1 level elevation in intestinal mucosa epithelial cells in active stage of IBD. Immunohistochemistry was applied to evaluate the specific role of Fra-1 in active stage of IBD. It was found that the number of Fra-1 positive inflammatory cells in intestinal epithelial cells was obviously increased in active stage $(\mathrm{P}<0.05)$. It indicated there may exist factors to induce Fra- 1 expression in active stage of IBD, thus Fra-1 played a critical role in this stage (Fig. 6). 


\section{Discussion}

IBD, including Crohn's disease and ulcerative colitis, is a group of chronic inflammatory diseases in the gastrointestinal tract. Its pathogenesis is still unclear, which is generally thought to be associated with genetic factors, environmental factors, and the imbalance of intestinal flora. IBD is not life-threatening, but the patients may appear recurrent abdominal pain, diarrhea, and vomiting, seriously affecting the quality of life.

In clinic, most patients obtain relief through the immunomodulatory therapy, especially the immune inhibitors and biological agents. However, a variety of patients are easy to relapse and difficult to heal. Thus, the role of inflammatory reaction in IBD remission and relapse attracts more and more attention.

Fra-1 is one of the members of the Fos family that contains seven members in mammals. Central SH2 domain and SOCS module composed of 40 amino acids exist in the protein structure of each member of the family. JAK/STAT signaling pathway can quickly activate Fra-1 gene transcription and expression, while Fra-1 protein can inhibit STAT continuous activation, thus forming negative feedback. Earlier study found that Fra-1 expression in intestinal mucosal epithelial cells significantly upregulated in IBD patients at remittent stage (11). Higher Fra-1 expression, shorter IBD recurrence time, suggesting Fra-1 may be a risk factor of the IBD deterioration $(12,13)$. Cell proliferation and damage repair assays demonstrated that Fra-1 overexpression suppressed intestinal mucosal epithelial cell proliferation and damage repair. Therefore, Fra-1 upregulation might be one of the important mechanisms of IBD relapse. Downregulating Fra-1 expression or inhibiting its upregulation may be effective means to prevent or delay IBD relapse.

It was reported that various proinflammatory signaling pathways may be related to Fra-1 upregulation in intestinal mucosal epithelial cells of IBD patients at remittent stage, such as STAT1, STAT6, PKA-C $\gamma$, and CREB (14-17). p-STAT1, p-STAT6, p-PKA-C $\gamma$, and p-CREB levels in intestinal mucosal epithelial cells also increased compared with healthy people and showed significant positive correlation with Fra-1. It further supported the hypothesis that Fra-1 was induced by multiple proinflammatory signaling pathways. Therefore, the strategy of inhibiting Fra-1 expression in intestinal mucosal epithelial cells could be used to explore broad-spectrum anti-inflammatory drugs. Animal models and clinical trials revealed that intestinal worms can modify the inflammation in intestinal mucosa epithelial cells, thus to play a treatment role on IBD. Lin et al (18) reported a case of applying worms (Trichuris trichiura) to induce and maintain intractable IBD at remittent stage that cannot be relieved by mesalazine, 6 -mercaptopurine, and high dose hormone. Studies reported the characteristics of intestinal mucosal epithelial cells gene expression profile, cellular immunity, and histopathology in IBD under active and remittent stages, while application of Trichuris trichiura induced IBD relief may be related to Fra-1 downregulation in intestinal mucosal epithelial cells $(19,20)$. Trichuris trichiura engraftment in the intestine may induce immune response produced by IBD patients aiming to discharge the worm, which is named $\mathrm{IL}-22^{+} \mathrm{T}$ cell-mediated immune response. As an additional effect, IL-22 induces antibacterial peptides expression and promotes the repair of the epithelial barrier to induce IBD into remission, thus to play a treatment role.

Apoptosis related proteins play critical roles in the inflammatory reaction of IBD. It was revealed that Bcl-2, Survivin, $\mathrm{Bcl}-\mathrm{xL}$, and c-Myc are the members of inhibitor-of-apoptosis (IAP) family. The protein structure of each member contained a BIR module composed of 70 amino acids. IAP can inhibit apoptosis and regulate cell cycle. IAP increased in the G2/M phase of cell cycle. Once survivin was damaged during this period, caspase-3 activity enhanced to induce cell apoptosis, indicating that survivin played an important role in cell apoptosis. Bcl-2, Survivin, Bcl-xL, and c-Myc levels obviously declined in the intestinal mucosal epithelial cells of IBD at remittent stage, suggesting they may participate in intestinal mucosa epithelium repair to alleviate IBD. Our results exhibited that Fra-1 overexpression markedly inhibited Bcl-2, Survivin, Bcl-xL, and c-Myc expression, revealing Fra-1 weakened the protective effect of intestine mucosa through suppressing their expression.

Fra-1 overexpression in intestinal mucosal epithelial cells elevated the risk of IBD relapse by weakening the protect effect and restraining the damage repair of intestinal mucosa in IBD at remittent stage. Thus, inhibiting Fra-1 expression facilitates to IBD remittent maintenance and recurrence delay.

\section{References}

1. Li Y, de Haar C, Chen M, Deuring J, Gerrits MM, Smits R, Xia B, Kuipers EJ and van der Woude CJ: Disease-related expression of the IL6/STAT3/SOCS3 signalling pathway in ulcerative colitis and ulcerative colitis-related carcinogenesis. Gut 59: 227-235, 2010.

2. Li Y, Nuij VJ, Baars JE, Biermann K, Kuipers EJ, Peppelenbosch MP, de Haar C and Janneke van der Woude C: Increased suppressor of cytokine signaling-3 expression predicts mucosal relapse in ulcerative colitis. Inflamm Bowel Dis 19: 132-140, 2013.

3. Li Y, de Haar C, Peppelenbosch MP and van der Woude CJ: SOCS3 in immune regulation of inflammatory bowel disease and inflammatory bowel disease-related cancer. Cytokine Growth Factor Rev 23: 127-138, 2012

4. Fang K, Bruce M, Pattillo CB, Zhang S, Stone R II, Clifford J and Kevil CG: Temporal genomewide expression profiling of DSS colitis reveals novel inflammatory and angiogenesis genes similar to ulcerative colitis. Physiol Genomics 43: 43-56, 2011.

5. Linke A, Goren I, Bösl MR, Pfeilschifter J and Frank S: Epithelial overexpression of SOCS-3 in transgenic mice exacerbates wound inflammation in the presence of elevated TGF-beta1. J Invest Dermatol 130: 866-875, 2010.

6. Linke A, Goren I, Bosl MR, Pfeilschifter J and Frank S: The suppressor of cytokine signaling (SOCS)-3 determines keratinocyte proliferative and migratory potential during skin repair. J Invest Dermatol 130: 876-885, 2010.

7. Planell N, Lozano JJ, Mora-Buch R, Masamunt MC, Jimeno M, Ordás I, Esteller M, Ricart E, Piqué JM, Panes J and Salas A: Transcriptional analysis of the intestinal mucosa of patients with ulcerative colitis in remission reveals lasting epithelial cell alterations. Gut 62: 967-976, 2013.

8. Broadhurst MJ, Leung JM, Kashyap V, McCune JM, Mahadevan U, McKerrow JH and Loke P: IL-22+ CD4+ T cells are associated with therapeutic Trichuris trichiura infection in an ulcerative colitis patient. Sci Transl Med 2: 60ra88, 2010.

9. Fukui H, Sekikawa A, Tanaka H, Fujimori Y, Katake Y, Fujii S, Ichikawa K, Tomita S, Imura J, Chiba T and Fujimori T: DMBT1 is a novel gene induced by IL-22 in ulcerative colitis. Inflamm Bowel Dis 17: 1177-1188, 2011.

10. Goldsmith JR, Uronis JM and Jobin C: Mu opioid signaling protects against acute murine intestinal injury in a manner involving Stat3 signaling. Am J Pathol 179: 673-683, 2011. 
11. Vaishnava S, Yamamoto M, Severson KM, Ruhn KA, Yu X, Koren O, Ley R, Wakeland EK and Hooper LV: The antibacterial lectin RegIIIgamma promotes the spatial segregation of microbiota and host in the intestine. Science 334: 255-258, 2011.

12. Mukherjee S, Zheng H, Derebe MG, Callenberg KM, Partch CL, Rollins D, Propheter DC, Rizo J, Grabe M, Jiang QX and Hooper LV: Antibacterial membrane attack by a pore-forming intestinal C-type lectin. Nature 505: 103-107, 2014.

13. Murano T, Okamoto R, Ito G, Nakata T, Hibiya S, Shimizu H, Fujii S, Kano Y, Mizutani T, Yui S, et al: Hes1 promotes the IL-22-mediated antimicrobial response by enhancing STAT3-dependent transcription in human intestinal epithelial cells. Biochem Biophys Res Commun 443: 840-846, 2014.

14. Ahmad R, Chaturvedi R, Olivares-Villagómez D, Habib T, Asim M, Shivesh P, Polk DB, Wilson KT, Washington MK, Van Kaer L, et al: Targeted colonic claudin-2 expression renders resistance to epithelial injury, induces immune suppression, and protects from colitis. Mucosal Immunol 7 : 1340-1353, 2014.
15. Bian Z, Li L, Cui J, Zhang H, Liu Y, Zhang CY and Zen K: Role of miR-150-targeting c-Myb in colonic epithelial disruption during dextran sulphate sodium-induced murine experimental colitis and human ulcerative colitis. J Pathol 225: 544-553, 2011.

16. Jiang R, Tan Z, Deng L, Chen Y, Xia Y, Gao Y, Wang X and Sun B: Interleukin-22 promotes human hepatocellular carcinoma by activation of STAT3. Hepatology 54: 900-909, 2011.

17. Dang CV: MYC on the path to cancer. Cell 149: 22-35, 2012

18. Lin CY, Loven J, Rahl PB, Paranal RM, Burge CB, Bradner JE, Lee TI and Young RA: Transcriptional amplification in tumor cells with elevated c-Myc. Cell 151: 56-67, 2012.

19. Naher L, Kiyoshima T, Kobayashi I, Wada H, Nagata K, Fujiwara H, Ookuma YF, Ozeki S, Nakamura S and Sakai H: STAT3 signal transduction through interleukin-22 in oral squamous cell carcinoma. Int J Oncol 41: 1577-1586, 2012.

20. Dunn ET, Taylor ES, Stebbings S, Schultz M, Butt AG and Kemp RA: Distinct immune signatures in the colon of Crohn's disease and ankylosing spondylitis patients in the absence of inflammation. Immunol Cell Biol 94: 421-429, 2016. 